\title{
UM JUSTO PREÇO PARA O AÇÚCAR: A VALORIZAÇÃO ARTIFICIAL DO AÇÚCAR BRASILEIRO NA ORDEM DO DIA, 1895-1928
}

\author{
A FAIR PRICE FOR SUGAR: \\ ARTIFICIAL ENHANCEMENT OF BRAZILIAN SUGAR \\ ON THE AGENDA, 1895-1928
}

\author{
Roberta Barros Meira \\ Universidade da Região de Joinville, Santa Catarina, Brasil, rbmeira@gmail.com
}

\begin{abstract}
Resumo. Este artigo discute as propostas de valorização do açúcar formuladas durante a Primeira República, através da promoção da política da concessão de prêmios ou dos convênios açucareiros. Nesse sentido, o artigo examina os resultados das medidas que visavam o aumento dos preços no mercado interno brasileiro, acompanhando a natureza da composição das propostas feitas tanto por produtores, como estadistas e técnicos nas duas áreas de produção do país. Para isso, se analisam os anais do I Congresso Nacional da Agricultura e das conferências açúcareiras de 1902, 1905 e 1911, alguns periódicos técnicos, como a revista da Sociedade Nacional da Agricultura, A Lavoura, e o Boletim do Ministério da Agricultura, Indústria e Comércio e alguns trabalhos estrangeiros que versavam sobre as políticas de valorização na Europa.
\end{abstract}

Palavras-chave: açúcar; políticas agrícolas; Brasil; prêmios.

Abstract. This article discusses the proposals for enhancement of sugar made during the First Republic, by promoting the granting of awards or agreements of the sugar policy. In this sense, the article examines the results of these measures aimed at increasing prices in the Brazilian domestic market, following the nature of the composition of these proposals made by producers, statesmen and technical in the two production areas of the country. For this, we analyze the annals of sugar congresses that took place during the First Republic, technical journals, such as the journal of the National Agricultural Society A Lavoura, and the Boletim do Ministério da Agricultura, Indústria $e$ Comércio and some foreign works that focused on valorization policies of sugar in Europe.

Key words: sugar; agricultural politics, Brazil; bounties.

Recebido: 11 de maio de 2014. Aprovado: 21 de julho de 2014.

Am. Lat. Hist. Econ., año 22, núm. 2, mayo-agosto, 2015, pp. 135-159 


\section{INTRODUÇÃO}

$\mathrm{E}$ ste artigo está dividido em duas sessões. Na primeira aborda-se o papel da defesa dos prêmios na promoção do chamado "justo preço" para o açúcar. O texto recorre à parca historiografia existente, em parte voltada para as políticas de valorização artificiais pensadas para o setor cafeeiro e questiona, com base em fontes diversas, as interpretações que apontam para a irrelevância destas discussões e debates, uma vez que o sistema de prêmios não chegou a vigorar no país. Na segunda parte, com base nas fontes produzidas pela Sociedade Nacional da Agricultura e pelo Ministério da Agricultura, Comércio e Obras Públicas, investiga-se a atuação dos convênios açucareiros, lançando luz sobre a importância do mercado interno já neste momento.

\section{UM DEBATE ACALORADO SOBRE A ADOÇÃO DO SISTEMA DE PRÊMIOS NO SETOR AÇUCAREIRO BRASILEIRO}

É de recordar que em muito influenciaram a defesa de uma atuação mais ativa por parte do Estado na implementação de uma política de valorização dos preços do açúcar as medidas de defesa aplicadas na produção cafeeira. Mendonça (1977) afirma que foram constantes os reclamos e pedidos de solução e amparo para a decadente lavoura cafeeira fluminense, que já vinha operando com pouca margem de lucro, tendo o quadro agravado pela baixa do preço do produto. Essa estratégia foi utilizada como meio de enfrentar as baixas nos preços do café no período, notando-se uma combinação de recursos nacionais e estaduais em prol desse objetivo.

Em 1902, há notícias de que Quintino Bocaiúva ${ }^{1}$ tentava colocar em prática um plano que contivesse os efeitos da superprodução cafeeira, buscando a união entre os estados cafeicultores. Mais tarde, o avanço dessas discussões levaria a uma ação coletiva do setor cafeeiro à crise dos preços, ou seja, o Convênio de Taubaté. ${ }^{2}$ Como observa Mendonça (2008), o modelo de atuação do Estado buscava minimizar a extensão de uma crise que advinha da produção, utilizando para isso medidas externas às unidades produtivas (p. 88). Em 1906, a revista A Lavoura (setembro-novembro, pp. 351-352) publicaria o parecer de uma comissão que representava as associações e sindicatos agrícolas existentes nos diversos estados brasileiros. ${ }^{3}$

\footnotetext{
${ }^{1}$ Quintino Bocaiúva foi ministro das Relações Exteriores, sendo que em 1902 ocupava o cargo de presidente do estado do Rio de Janeiro (1900-1903).

${ }^{2}$ Ver artigos 1 e 2 da Lei 990, de 4 de julho de 1906, (Brasil 1889-1926).

${ }^{3} \mathrm{O}$ objetivo da comissão era estudar em comum a situação da lavoura de cana e da industria açucareira no Brasil e indicar medidas que pudessem ser postas em prática a fim de debelar a crise
} 
Intitulado pela revista "Em Defesa da Indústria Açucareira", o parecer enfatizava o fato dos produtores de café recorreram à intervenção do Estado para valorizar, regularizar e desenvolver o consumo deste produto, tentando resguardar a sua posição de preponderância no mercado mundial.

Releva notar aqui que um dos pontos levantados seria o estabelecimento de um preço mínimo, garantindo com uma taxa sobre o imposto de exportação, ou seja, reproduzia-se a política de prêmios que marcava desde longa data os países ameaçados por uma superprodução. No entanto, entrava em cena não só os planos de valorização artificial para os produtos agrícolas com uma boa posição no mercado externo, no qual se enquadravam bem o café, mas também para aqueles que enfrentavam uma baixa neste mercado, como o açúcar. Em ambos os casos, as políticas de valorização foram seguidas pela ideia de um "justo preço". Os seus idealizadores valeram-se de tal nome para justificar diante dos consumidores tais estratégias, uma vez que segundo eles a preocupação era não deixar os preços tão desnivelados com o custo da produção e mais um acréscimo de um pequeno lucro. A maior vantagem seria o fim das oscilações de preços que caracterizavam estes anos e o aumento da capacidade produtiva, pois estes pequenos lucros permitiriam modernizar a produção.

Como não poderia deixar de ser, no que se refere à produção açucareira, a atenção dos usineiros brasileiros estava voltada para o açúcar de beterraba. Os europeus colocaram em prática um sistema que se baseava na concessão de prêmios aos produtores que exportassem, financiado pela cobrança de uma taxa sobre o açúcar consumido internamente, o que também acabava gerando a alta dos preços internos do açúcar nestes países. George Martineau (1910) atribuiria o fabuloso progresso da indústria açucareira de beterraba justamente aos prêmios, propiciado além dos prêmios pela alta artificial dos preços que eles geravam nestes países. No Brasil, a estratégia que se pretendia colocar em prática não era muito distinta. Seria o Estado que se responsabilizaria tanto pela cobrança deste imposto, assim como pela sua administração e a regularização da exportação dos excessos de açúcar. A diferença seria que devido às frequentes queixas dos consumidores, passou-se a se defender que os prêmios seriam dados apenas nos anos de crise. Como justificava Augusto Ferreira Ramos:

Se a safra é escassa, os preços internos se mantêm naturalmente elevados, como sempre tem acontecido, e ninguém buscará aproveitar-se do preço fixo em aberto; se a safra é grande, baixem os preços internos, até atingirem o "justo preço", sem que lhes acuda o interventor. Se, porém, a depressão tende a acentuar-se, o produ-

da industria açucareira. Os seus membros eran Corrêa de Brito, Euzebio de Andrade, Francisco da Rocha Lima, Curvello de Mendonça, Augusto Ramos, Motta Vasconcellos. 
tor não mais se utiliza das ofertas dos consumidores, mas busca o interventor e lhe vende pelo justo preço o gênero que não logrou encontrar fora melhor cotação. Mas, a produção tem limite e, dentro em pouco, vendido ao interventor o excesso produzido, começa a escassear o gênero e, naturalmente, sobem os preços. Tornase superior ao "justo preço" o preço do mercado interno, e ninguém mais recorre ao interventor, que volta ao seu estado contemplativo, assistindo à luta dos interessados nos mercados em plena liberdade (Ramos, agosto-dezembro, 1911, p. 273).

Augusto Ferreira Ramos era uma espécie de consultor dos produtores de café e açúcar do Sudeste do Brasil em matéria de valorização artificial da produção. Ramos era engenheiro, formado na Escola Politécnica do Rio de Janeiro. Dentre os muitos cargos de destaque, foi presidente da Sociedade Nacional de Agricultura e foi o inspirador do convênio de Taubaté. Experiência que levaria para formular o plano de defesa do açúcar, apresentado na Quarta Conferência Açucareira em Campos dos Goytacases, no Rio de Janeiro, em 1911. Ademais, foi o representante do estado de São Paulo na Conferência Açucareira da Bahia e do Espírito Santo. Além de dirigir a revista $O$ Fazendeiro (Poliano, 1945).

Ora, a defesa dos prêmios no Brasil se inseriu em um quadro de discussões sobre a valorização artificial do açúcar posta em prática por vários países por um longo período. ${ }^{4}$ Nesse sentido, deve-se considerar a influência de uma gama de escritos estrangeiros que seria recuperada pelos defensores dos prêmios em seus textos para justificar a sua adoção no Brasil. Trabalhos como os de Louis Grandeau (químico e agrônomo francês), Yves Guyot (economista francês), dentre outros ${ }^{5}$ eram constantes nos discursos da época. E este pensamento, de modo geral, considerava que os prêmios instituídos em países como a França desde meados do século XVII foram essenciais para o incremento excepcional do açúcar de beterraba. Além de permitir o desenvolvimento técnico, os prêmios permitiam ao açúcar de beterraba a competir vitoriosamente com o açúcar de cana até mesmo em países vizinhos do Brasil, como no caso do Uruguai.

Impossível não reconhecer que o açúcar de beterraba já há algum tempo tornara-se o principal rival do açúcar de cana. Em 1907, um relatório feito pelo governo do Estados Unidos sobre a produção e o consumo do açúcar seria muito esclarecedor neste particular ao afirmar que não existia outro exemplo "de outro qualquer gênero da natureza, cuja produção mundial tenha tido tão rápido e espantoso desenvolvimento como o do

\footnotetext{
${ }^{4}$ Um exemplo seriam os textos e discussões produzidos durante as conferências internacionais em 1854, 1878, 1888 e 1902.

${ }^{5}$ Alguns outros autores estrangeiros citados seriam Boizard, Tardieu, Emile Legier, Jules Helot, etc.
} 
açúcar de beterraba" (Comissão de Inquérito sobre a Indústria do Açúcar no Brasil, 1907, p. 6). No entanto, devemos relembrar que essa concorrência influenciaria no desenvolvimento da produção de açúcar de cana, fazendo com que a produção desses dois tipos de açúcar caminhasse quase junta com um desenvolvimento particularmente rápido, principalmente em Cuba e Java (sNA, 1924, p. 22).

A despeito da grande divulgação conquistada pelos avanços técnicos em relação à produção do açúcar de beterraba e que não deixou de ser apontada pelos usineiros e técnicos brasileiros, a segurança fornecida pelo erário público, sob a forma protetora dos chamados bounties ou prêmios de exportação em muito pareciam tirar o sono dos produtores de açúcar de cana, uma vez que a concorrência mundial tornava-se cada vez mais acirrada.

Deve-se ir prudentemente, no entanto, quando se fala na defesa dos estímulos artificiais adotados principalmente pela Europa, tais como os prêmios, no Brasil. Não era exatamente uma defesa aguerrida que se via por parte de todos, mas sim uma profunda desconfiança e mesmo oposição por parte dos produtores do Nordeste. Não que não houvesse, antes disso, distanciamentos entre as duas regiões produtores de açúcar do país, mas os atritos sempre pareceram ser muito mais decorrentes da forma como seriam aplicadas as novidades provenientes do estrangeiro.

É de lembrar que duro foi o golpe sentido pelos produtores de açúcar nordestinos com a entrada não só do açúcar de beterraba, mas da enorme produção de açúcar de cana dos rivais do açúcar brasileiro, como Cuba, levando a uma assustadora perda do mercado externo. Não se detêm aqui nos pormenores desse processo, pois o que interessa neste momento é intender a conjuntura que gerou não só a defesa deste ideal, mas que também permitiu o insucesso dos prêmios de exportação no Brasil.

Já nas primeiras décadas do século XX, o eixo dinâmico do comércio do açúcar brasileiro havia se afirmado definitivamente no mercado interno, embora não se pudesse dizer que as exportações ficassem em um plano secundário, uma vez que dela dependia o escoamento de toda excesso que não fosse absorvido pelo consumo nacional, o que não era de pouca monta, posto que não só a produção do Nordeste estava em franca expansão, mas também a do Sudeste. Ora, mesmo se os preços do açúcar não fossem tão compensatórios tornaram-se um necessário aporte para manter o equilíbrio do mercado interno.

É plausível supor que alguns anos seriam mais negros, fosse pelo jogo do próprio comércio ou pelo aumento da produção do açúcar de cana e de beterraba. Não se pode negar que o ano de 1901 foi um destes em que o sempre precário equilíbrio da produção de açúcar e o seu consumo se rompeu, ou seja, o resultado imediato seria uma queda brusca nos preços. 
O desenvolvimento das usinas propiciado pelo aumento dos preços do açúcar na década de 1890-1900 e os auxílios concedidos pelos estados seriam obstados pela crise que atingiu os produtores brasileiros. Um influente representante da indústria açucareira neste período, Miguel Calmon $\mathrm{Du}$ Pin e Almeida, que assumiu diversos cargos públicos entre os quais o de ministro da Agricultura, Indústria e Comércio, e o de presidente da Sociedade Nacional da Agricultura (Poliano, 1945), afirmava que a situação da indústria açucareira em 1901 era de completa ruína. ${ }^{6}$ Essa seria a mesma impressão que Gileno Dé Carlí, futuro presidente do Instituto do Açúcar e do Álcool (em diante IAA), e que estudou detidamente a indústria açucareira no Brasil, teria mais tarde quando ele defende que a caída dos preços do açúcar neste ano teve o efeito de um verdadeiro craque. Dos dez cruzeiros por arroba alcançados nos anos anteriores, em 1901, o açúcar chegaria a valer menos de quatro cruzeiros por arroba (Dé Carlí, 1937, pp. 28-29).

Naturalmente, não seria de se estranhar que a discussão sobre a adoção ou não dos prêmios tomasse fôlego neste ano. Ademais, também não há como passar desapercebido que 1901 foi o ano do Primeiro Congresso Nacional da Agricultura, organizado pela Sociedade Nacional da Agricultura. Insistimos, também, neste congresso, pois aí foram colocados em pauta os principais problemas e, consequentemente, as soluções propostas pelos produtores de açúcar.

Seja como for, a questão sempre vividamente discutida, pelas suas repercussões econômicas pelo aprofundamento da baixa dos preços, era a perda pelo açúcar brasileiro de alguns mercados anteriormente cativos, como no caso de Portugal e do Uruguai. Releva notar que ambos os países passaram a ser abastecidos por açúcar premiados, sendo no primeiro caso o açúcar de beterraba e no segundo arrebatado pelo produtor argentino (Couret, 1907, p. 166). Não haveria maiores razões para se acreditar num crescimento brusco da exportação do açúcar brasileiro. Mal-estar que seria perfeitamente descrito por Manoel Victorino (1907) na sua fala no Primeiro Congresso Nacional de Agricultura: "Nenhuma ilusão pode restar acercar da situação gravíssima da lavoura do nosso país. [...] Mercados novos ou não se criam ou se limitam a importação muito diminutas" (p. 14).

Outra situação cada vez mais problemática era o alento da produção de açúcar nos antigos estados outrora basicamente consumidores. Mesmo que não se pudesse falar ainda de autossuficiência, havia claramente um excesso quando se somavam os açucares locais com os enviados pelo Nordeste, o que tornava perceptível os obstáculos ao tão desejada estágio de equilíbrio do mercado interno nacional. Esse ponto de vista se tornaria

\footnotetext{
${ }^{6}$ Para que se possa avaliar os efeitos da crise de 1901 no mercado mundial de açúcar ver o já citado trabalho de Guyot (1901).
} 
uma preocupação não só da principal região produtora do país, mas também dos usineiros do Sudeste. Em um contexto que assomava no horizonte o problema da superprodução, a intenção geral passa a ser a defesa de um conjunto nacional, no sentido de um sistema harmonioso pelo menos quando o que estava em jogo eram os preços no mercado interno. Szmrecsányi (1979) defende que a crise de superprodução era uma questão de tempo, e só deixou de ocorrer já antes de 1930 por causa da crise do mosaico em 1925, a qual reduziu drasticamente a produção açucareira paulista.

Em verdade, como essa era uma crise mundial de superprodução, as medidas pensadas nos grandes países produtores de açúcar não deixaram de refulgir no Brasil. Algumas propostas mais radicais chegaram a reverberar entre os produtores brasileiros, mas foram rapidamente postas de lado, como foi o caso do contingenciamento da produção. Em 1911, Augusto Ferreira Ramos afirmava que existia na Alemanha uma lei que praticamente impunha a cada usina, ano por ano, o contingenciamento da sua produção (Ramos, agosto-dezembro 1911, p. 274). Foram os próprios usineiros que a solicitaram do governo, assim como os fazendeiros solicitaram do governo paulista proibir novas plantação de café (Brandão, 1912a). De fato, esse expediente só seria adotado mais tarde pelo IAA, criado em 1933, em um momento no qual já não se poderia negar os efeitos cada vez mais ruinosos da superprodução. Assim, a única medida que parecia mais razoável para os homens desse período foi o envio de uma parte da safra para o exterior.

Neste caso específico, realmente houve uma consonância entre as regiões. Esse compartilhamento da visão sobre o mercado interno pode ser notado tanto no fala do representante dos produtores de açúcar de Campos dos Goytacases, no Rio de Janeiro, Emmanuel Couret (1907, p. 169) (quem foi presidente da Associação Comercial de Campos dos Goytacases e proprietário da Usina Abbadia), que defendia que era necessário exportar açúcar para estabelecer o equilíbrio, como também no discurso do membro da Sociedade Auxiliadora da Agricultura de Pernambuco, Ignácio de Barros (1907), ao confirmar que no ano de 1901 e 1902 se exportou açúcar com manifesto prejuízo, "mas como tínhamos necessidade de exportá-lo, suportamos o prejuízo" (p. 106).

No entanto, parece que a similitude do plano de resguardar o mercado interno termina neste quesito. A ideia esposada pelos representantes do Sudeste acerca de atingir o estado de equilíbrio passava pelo já conhecido sistema de prêmios. Para eles, o mercado mundial de açúcar encontravase em uma posição insofismável, ou seja, o preço do açúcar brasileiro era sempre maior do que o preço de venda dos países que gozavam de vantagens dos prêmios de exportação e por isso se perdia ou não se conseguia abrir novos mercados. A fala de Emmanuel Couret, como representante 
de Campos dos Goytacases, confirma essa preocupação por parte dos produtores do Sudeste. Segundo ele, os produtores clamavam que sem prêmios a lavoura do açúcar não poderia se manter e muito menos progredir. Vê-se também a preocupação com o mercado interno através das suas observações sobre os seguintes aspectos. Se as estatísticas apontavam que o Brasil produzia mais ou menos 5000000 de sacas de açúcar, era certo que pelo menos 2000000 de sacas não seriam absorvidas pelo mercado interno, isto é, esse excesso criava uma situação propicia para as especulações e os aviltamento dos preços (Couret, 1905).

Não se pode negar que a preocupação dos usineiros do Sudeste era resguardar o seu próprio mercado da invasão dos açucares nordestinos. A visão recorrente entre eles era de que os excessos de açúcar atravancavam o seu desenvolvimento. Dai os prêmios soarem como a melhor saída para este problema, pois possibilitariam modernizar as usinas e o cultivo da cana, baixando assim o preço de custo e alçando o açúcar a uma posição confortável no mercado internacional.

A questão que se coloca aqui é a adesão que o sistema percebido e organizado pelos europeus de valorizar a sua produção artificialmente ganharia no Brasil de então. Como foi apontado anteriormente, a adesão do principal produto de exportação do país, o café, acabaria funcionando como um gatilho para outros produtos, como o açúcar. Releva notar que neste caso, a estratégia seria posta em marcha pelos mesmos homens. Para que se tenha uma ideia mais precisa desta inter-relação, pode-se acompanhar, particularmente, os trabalhos de Augusto Ferreira Ramos no Congresso Nacional da Agricultura em 1901 e nas conferências açucareiras de 1902, 1905 e 1911. É preciso lembrar que ele não só teria uma participação ativa na formulação do convênio de Taubaté, mas seria uma das principais vozes nos congressos e conferências açucareiras em prol dos prêmios, além de formular um plano de defesa do açúcar escorado nos prêmios na Quarta Conferência Açucareira, em 1911, em Campos dos Goytacases, no estado do Rio de Janeiro.

Ramos (1907) chamava atenção para o fato de que a limitação interna do consumo de açúcar era motivada pela baixa do café, gerada pela sua superprodução e, consequentemente, a diminuição das rendas públicas e de todas as outras rendas. A superprodução do açúcar agravada então pela crise cafeeira só seria aliviada se o país mandasse os excessos para o mercado estrangeiro e a única forma de obtê-lo seria a adoção do sistema de prêmios de exportação.

Fica manifesta, assim, que a tônica do pensamento de Augusto Ferreira Ramos era sem dúvida pautada na importância do café no conjunto nacional. Daí a importância de se pensar políticas de valorização voltadas para o mercado externo. A salvação para o açúcar não seria outra, mas 
neste particular, o mercado nacional predominava sobre o mercado internacional, ou seja, era necessário incentivar a exportação como forma de desafogar o mercado interno dos excessos dos açúcares do Nordeste. O estratagema que se pensava colocar em prática faria com que o açúcar exportado a $9 \$ 000$ réis por saca de $60 \mathrm{~kg}$ e que obtinha $19 \$ 000$ no mercado nacional, pudesse ser exportado com um valor a mais, possibilitado pelo prêmio de $6 \$$, escoando assim mais facilmente para o estrangeiro.

Augusto Ferreira Ramos (1907) entendia que o prêmio de exportação possuía um valor irresistível e universal, pois nos mercados estrangeiros desalojava os açucares que não tivessem um baixo custo de produção, provocando e alimentando as trocas e servindo como um elemento comercial de primeira ordem. Por outro lado, no mercado interior ele atrairia para os portos de exportação açúcar de todas as partes, provocando uma alta movimentação do produto e restabelecendo um justo equilíbrio entre os preços de produção e consumo, isto é, o prêmio funcionaria como um regulador do mercado. Ademais, defendia que esse auxílio era benéfico aos consumidores por impedir uma ulterior carestia do produto. É essa mesma função protetora que traduzia a influência economia dos prêmios e o alçava a posição da mais nova arma salvadora da indústria sacarina do país.

No estrangeiro é uma arma de combate e de propaganda; no interior é um elemento igualitário, equitativo e conservador. É um aríete e uma couraça e traz sempre no tope, flutuando aos olhos comerciais do mundo inteiro, o pavilhão vigoroso da pátria (Ramos, 1907, pp. 53-54).

Um importante aspecto a ser ressaltado é que, neste exato momento, a política de prêmios de exportação direcionados para o açúcar passara a sofrer um forte ataque, liderado principalmente pela Inglaterra. Desde o final do século XIX, o mercado internacional de açúcar travava uma guerra de subsídios à produção e à exportação, que se somavam às tarifas alfandegárias proibitivas entre os produtores europeus. A Inglaterra, maior país consumidor neste momento, aboliu os direitos de entrada e lutava, desde 1865 , pela adoção de medidas antiprotecionistas como forma de resguardar a sua indústria de refinação de açúcar (Almeida, 2001). Heitor Pinto de Moura Filho (2007) demonstra que nas duas últimas décadas do século XIX, quando os efeitos dos subsídios se fizeram mais fortes, ocorreu um crescimento das importações inglesas de açúcar de beterraba, seja bruto ou refinado. Essa preferência pelo açúcar de beterraba pode ser vista como uma decorrência dos prêmios à exportação concedidos pelos principais produtores de açúcar europeus em função da origem e do tipo de produto importado. $\mathrm{O}$ maior crescimento se concentrou nos açúcares refinados, majoritariamente de beterraba, e beneficiários dos subsídios.

Por outro lado, era manifesta a preocupação dos grandes produtores que concediam prêmios, como a França e a Alemanha, em não prejudicar 


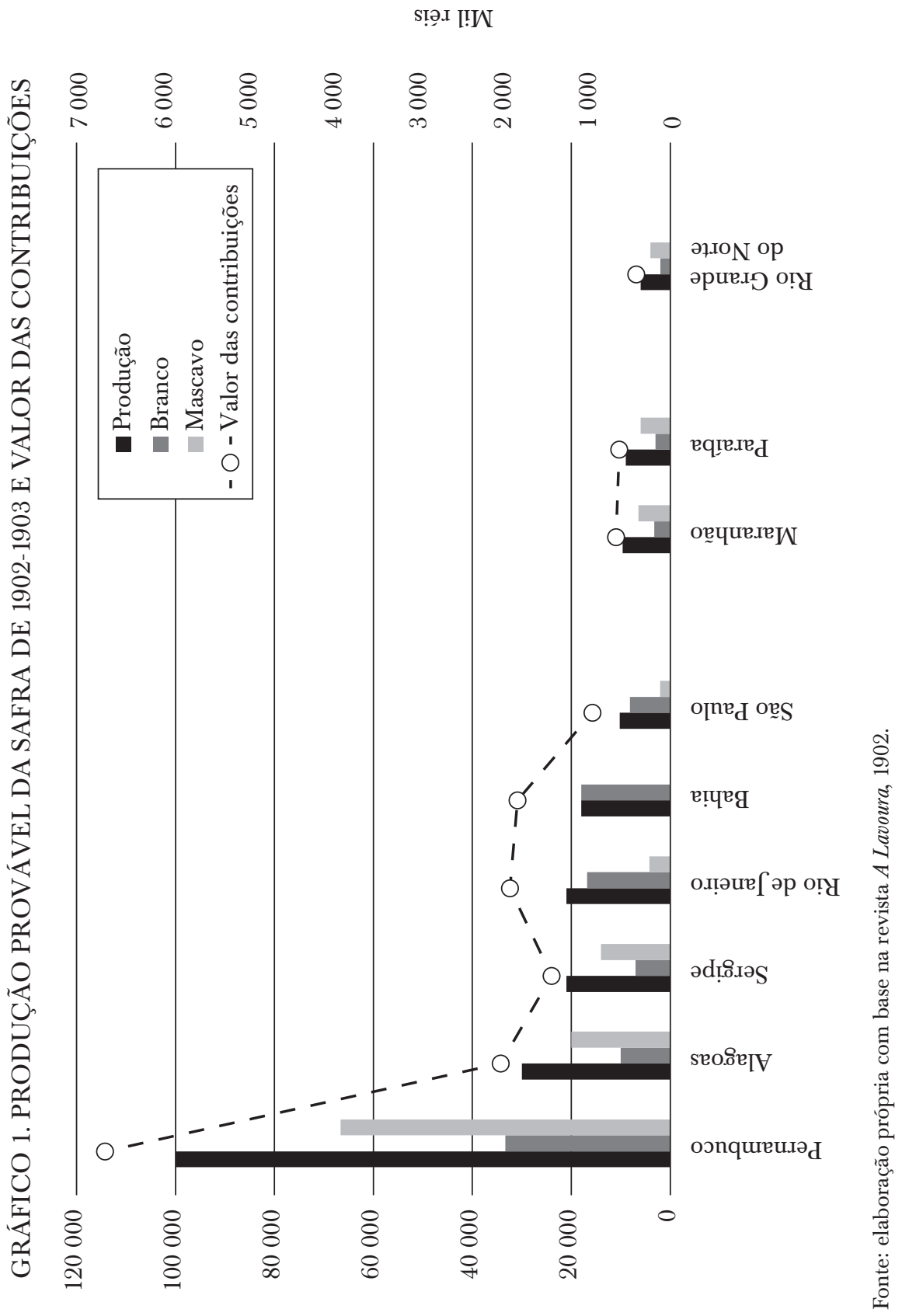

sеретәио $L$ 
a sua indústria açucareira. Pela importância do assunto, não impressiona que esta tenha sido a tônica de várias conferências açucareiras -como nas duas Conferências Internacional de Londres em 1854 e em 1888 e nas conferências de Bruxelas em 1878 e 1902- que teriam como pauta predominante do programa o papel que os prêmios açucareiros tinham assumido.

O estadista Garcia Pires, cotado para ser o representante do Brasil na Convenção durante a Conferência Açucareira da Bahia, levantaria uma questão importante para explicar o interesse da Inglaterra ao enfatizar que o Convênio de Bruxelas não tinha valor, pois nenhuma nação do mundo tirou mais vantagem dos prêmios do que a própria Inglaterra com a sua indústria de refinação, deixando as suas próprias colônias na miséria (SNA, 1905, p. 102). A sua mudança de postura quando se tratava dos prêmios só surgiu pelo receio de que essas colônias se reunissem a União Americana. Nesse sentido, a convocação do Convênio seria apenas uma maneira de elevar a seu poder sobre a comercialização do açúcar. Gnaccarini (1997) concorda que

Ao propor em 1900, agora com mais sucesso, as medidas antiprotecionistas adotadas em boa medida pelo Convênio de Bruxelas, pelas quais vinha lutando desde 1865, o interesse da Inglaterra no controle mundial da produção de açúcar era uma dedução lógica do liberalismo econômico inglês. A supremacia inglesa no comércio mundial dependia de que a divisão internacional do trabalho não fosse submetida a desequilíbrios muito profundos. O crescimento agrícola europeu se concorresse efetivamente com a produção colonial, poderia ser um dos fatores desse desequilíbrio. Isto era especialmente certo se a produção metropolitana se expandisse à custa de proteções antilivre-cambistas, e fosse acompanhada de superprodução de alimentos e matérias-primas de origem agrícola (p. 317).

Ademais, outro objetivo da Inglaterra em estabelecer o acordo de Bruxelas era rivalizar com a política econômica açucareira estadunidense. Nesse período, Estados Unidos já havia estabelecido tarifas preferenciais e de acordos bilaterais de comércio, como os que vinham estabelecendo no caso do açúcar, com alguns países recém-libertos do colonialismo europeu, com alguns países latino-americanos de sua área de influência, e mesmo com nações europeias industrialmente atrasadas: Espanha, Cuba e Filipinas, México, Peru e Argentina. A Inglaterra buscava, desse modo, enfrentar o fechamento do mercado estadunidense e a inclusão nele de outras áreas do comércio mundial (Mendonça, 1903, p. 103).

No que diz respeito ao Brasil, não se pode estranhar que os produtores pernambucanos, atados em parte ao mercado externo, fossem os mais ferrenhos opositores aos prêmios e os maiores defensores do Brasil passar a ser signatário do Convênio de Bruxelas. Um fantasma parecia ainda po- 


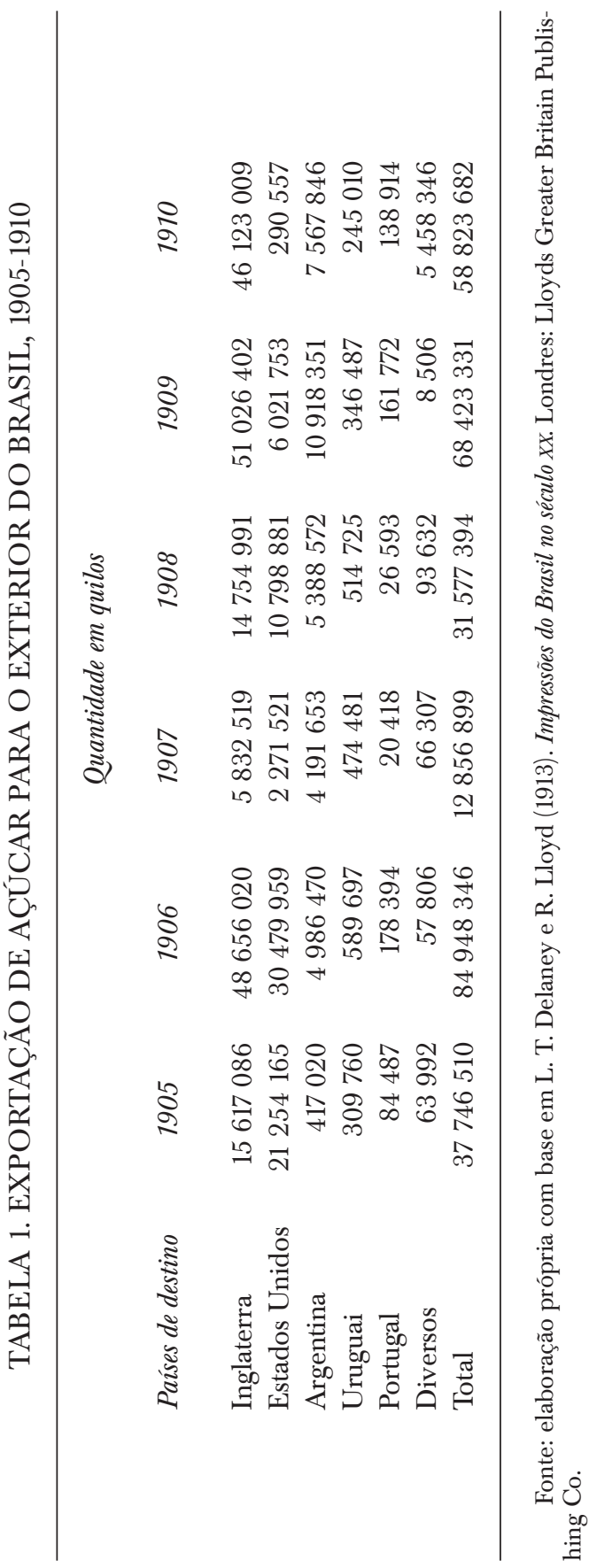


voava-lhes as mentes, sendo que desta vez não era compartilhado pelo Sudeste, ou melhor, ainda se pensava na reconquista dos mercados europeus. Alegava-se que a redução das tarifas estrangeiras levaria a indústria açucareira nacional a melhorar a sua eficiência e concorrer vantajosamente no mercado internacional, já que contava com vantagens naturais.

Mas, muito mais importantes que esses argumentos um pouco irreais na conjuntura do país naquele momento eram os elos comerciais que o açúcar brasileiro ainda mantinha com a Inglaterra e com Estados Unidos.

Embora não negassem que os prêmios seriam um estímulo, os seus opositores enxergavam nele apenas uma ilusão, pois se devia lembrar que os dois principais compradores mundiais ameaçavam cobrar direitos compensatórios aos países que concedessem prêmios aos seus açucares. Um dos principais oradores dessa corrente, Estácio Coimbra ${ }^{7}$ (1907), era claro a respeito do tema: o país deveria assinar tratados de comércio, reduzir as tarifas das estradas de ferro, diminuir os fretes marítimos, alcançando assim à solução da crise do açúcar, sem haver necessidade de prêmios de proteção direta. Ademais, a sua defesa estava fortemente fundamentada na perda do mercado inglês. Assim, dizia que:

sabe-se que a Inglaterra retirou-se da Conferência de Bruxelas, em 1898, declarando que se reserva o direito de estabelecer medidas extras contra o açúcar oriundo de países que mantivessem o regime dos prêmios. Pergunto ao Congresso: é razoável que no atual momento de dificuldades para a população brasileira, adotemos o regime dos prêmios, estabeleçamos direitos de consumo sobre o açúcar, encarecendo assim um gênero de primeira necessidade? E que utilidade trará isto? Fará apenas com que incidamos nos direitos compensatórios ou adicionais que os Estados Unidos e a Inglaterra, muito legitimamente, porque se trata da defesa do açúcar de suas colônias, terão de adotar contra o nosso produto (Coimbra, 1907, pp. 158-175).

Apesar de toda essa preocupação tanto por parte dos adeptos dos prêmios como dos contrários, não houve nenhuma ação imediata por parte do governo. No entanto, devido mais às pressões internas, não foi possível manter uma posição neutra frente aos acordos internacionais, assim como tinha sido a prática anterior do país. Almeida (2001) aponta que o governo imperial manteve-se numa postura discreta, de recusa dos arranjos negociados de maneira pouco clara com vistas a defender primeiramente os interesses dos produtores de açúcar, submetidos à dura concorrência

\footnotetext{
${ }^{7}$ Estácio Coimbra era natural de Pernambuco, formado em direito e assumiria diversos cargos políticos, como deputado, senador, vice-presidente e presidente do estado de Pernambuco, ministro da Agricultura, etc. Ademais, era senhor de engenho.
} 
internacional. Mas, foi apenas em 1906, devido ao peso de Pernambuco na produção de açúcar nacional, que o Brasil passou a ser signatário do Acordo de Bruxelas. No entanto, os produtores de açúcar do Sudeste poderiam se jactar que em parte a sua postura era a mais acertada. Durante os poucos anos que o Brasil aderiu à Convenção de Bruxelas, de 19061910, não ocorreu nenhum aumento significativo das exportações brasileiras como previram os seus defensores (Instituto do Açúcar e do Álcool, 1972). Afora isso, se confirmaram os receios de que o preço no mercado interno poderia sofrer ainda mais com a entrada de produtos estrangeiros, sendo necessário que o Parlamento elevasse a taxa do imposto de importação já em 1908. Ou seja, o resultado dessa campanha para os produtores de açúcar do Nordeste seria quase nulo, posto que ele não solucionou a antiga questão do retorno ao mercado externo nem contribuiu para que desaparecesse o laço da superprodução no mercado interno.

Torna-se bem claro, diante de tudo isso, que embora os prêmios fossem considerados uma solução eficaz para a crise de preços por uma fração expressiva dos representantes do açúcar, eles foram frequentemente postos de lado. Havia uma grande preocupação com a dependência que o Nordeste ainda tinha dos mercados estrangeiros. Ademais, criava-se sempre uma ilusão nos anos em que os preços se recuperavam com uma maior demanda pelo açúcar brasileiro, seja por fatores climáticos na Europa ou mesmo por uma conjuntura de guerras, como seria no caso da primeira grande guerra. Mas, não é verdade que o Brasil não se valeu de medidas que visassem valorizar o seu açúcar no mercado interno. Embora, deve-se ressaltar que elas foram feitas sem a participação do Estado, sendo pensadas e postas em prática principalmente pelos produtores de açúcar pernambucanos. No mais, embora fossem baseadas igualmente na exportação dos excessos de produção, não se escoravam em prêmios, mas sim na compensação obtida com o aumento dos preços do açúcar no mercado interno pela diminuição dos estoques. Exemplo disso seriam 1895-1896 a estratégia de valorização organizada principalmente pela Associação Comercial Beneficente de Pernambuco em 1895-1896, os convênios açucareiros de 1901, 1905, dentre outros.

Como se sabe, a visão extremista do representante de Campos dos Goytacases no I Congresso Agrícola: "Reflitam bem os interessados e não percam um dia: o prêmio imediato ou o suicídio" (Couret, 1907, p. 26) não se fez realidade, mas aclara que a posição do Sudeste estava invariavelmente mediatizada pela necessidade de proteger os seus mercados da invasão do açúcar nordestino. Nesse sentido, o que importava mais do que os desvarios fantasiosos de recuperação do mercado externo naquele momento era sem dúvida aproveitar o potencial crescimento do mercado interno e a estabilização dos preços em patamares mais elevados. 
Um último aspecto que se pode analisar quando se analisa à questão dos prêmios é o fato de que as ideias, muitas vezes, são mais importantes do que os seus resultados. A inaplicabilidade dos prêmios naquele momento, por motivos diversos, não impediu que o debate em torno da sua adoção, ou não, fosse travado durante toda a Primeira República. Ou seja, eles não deixam de constituir uma das demandas que apontam para um crescente anseio de uma intervenção estatal mais direta no setor. Aspiração que seria atendida de forma plena no pós-1930 com a criação do IAA.

\section{A ESTRATÉGIA NORDESTINA: OS CONVÊNIOS AÇUCAREIROS}

Embora o Nordeste se negasse categoricamente a adotar o sistema de prêmios como um plano viável de valorização do açúcar no mercado interno, acabou por recorrer a um projeto próprio, imprimindo um tom que pudesse passar desapercebido aos países importadores de açúcar. Como de fato se deu, embora o país fosse penalizado em alguns anos por outros motivos, como pelos altos impostos de importação que incidia sobre o açúcar estrangeiro, considerado como subsídios pelos ingleses. De qualquer forma, a saída encontrada e largamente utilizada foi o envio de uma parte da safra para o exterior, o que era feito na sua quase totalidade pelos produtores de açúcar de Pernambuco. O resultado das discussões em torno deste problema foi a concepção de um projeto de fortalecimento da indústria sacarina brasileira formulado basicamente levando em consideração o ideal de alcançar um estado de equilíbrio, ou seja, exportar todo o excesso de açúcar que obstasse a manutenção de um certo nível de preço no mercado interno e que compensasse os resultados negativos auferidos com as vendas para o estrangeiro. Ou seja, era necessário um certo sacrifício para se alcançar o tão clamado "justo preço" no mercado interno. ${ }^{8}$

Se os produtores de Pernambuco não consideraram os prêmios como uma saída válida, acabaram por arcar com quase todo o peso das remessas de açúcar a baixos preços feitos para equilibrar o mercado interno. Não se deve estranhar o sucesso desta medida, uma vez que como já havia observado Eisenberg (1977), a proteção dada pelo governo brasileiro através das altas taxas de importação do açúcar permitia a esses produtores conseguirem altos preços no mercado interno através da restrição da oferta do produto, o que compensava as perdas com a parte do açúcar exportado (pp. 51-52). No entanto, para o sucesso desta iniciativa foi necessário a

\footnotetext{
${ }^{8}$ Na década de 1930, o IAA se valeria do mesmo recurso de exportar para o estrangeiro os excessos como forma de preservar os preços no mercado interno, denominando-as como cotas de sacrifício.
} 
formação de acordos e coligações entre alguns produtores de açúcar e comerciantes localmente. Sendo que somente mais tarde, buscou-se dar um passo mais amplo com o acordo com outros estados.

Sabe-se que as políticas de valorização do café foram orquestradas principalmente por São Paulo. Como não era de se estranhar, Pernambuco, como o maior estado produtor de açúcar do Brasil, buscaria organizar os passos dos planos de valorização. No entanto, pelo que se depreende das inúmeras tentativas de colocar em marcha esses planos, era a difícil integração dos seus atores. Apenas para se ter uma ideia da dificuldade que era colocar esses projetos em prática, é de registrar que a primeira tentativa de Pernambuco de utilizar este tipo de estratégia seria a nível local e mesmo assim acabou fracassando. Na safra de 1895-1896, sob o comando da Associação Comercial Beneficente de Pernambuco, fundada em 1839, alguns engenhos produziriam uma maior quantidade de açúcar bruto para a exportação, aumentando assim os preços no mercado interno. $\mathrm{O}$ argumento era de que se os engenhos produzissem somente açúcar bruto de exportação até outubro de cada ano ficariam livres da competição tanto do açúcar europeu de beterraba quanto do açúcar de cana, que chegavam aos mercados internacionais no fim de outubro e em dezembro respectivamente (Eisenberg, 1977, pp. 51-52). O esquema não daria certo desta vez, nem em uma nova tentativa feita em 1901. Nesse sentido, até aqui se quis deixar claro que mesmo localmente não seria fácil obter resultados positivos.

Aliás, convém observar que as tentativas de coligação desde o seu início estariam relacionadas com as condições do mercado externo, mais especifícamente, com uma forte queda nas vendas, sendo um exemplo ilustrativo deste fato a abolição do tratado Blaine-Mendonça, em 1995. John Schulz (2013) aponta que "todos os ministros da Fazenda do Encilhamento, bem como todos os que serviram a Floriano Peixoto, apoiaram um tratado com os Estados Unidos que permitia ao açúcar brasileiro entrar nesse país livre de impostos, em troca de concessão de um privilégio similar no Brasil para os produtos industrializados exportados pelos Estados Unidos" (p. 194). Esse tratado entre o Brasil e o Estados Unidos seria negociado nos governos de Ouro Preto e Rui Barbosa, mas só vigorando de fato a partir de fevereiro de 1891, já no mandato de Lucena. No entanto, a sua duração seria curta, pois seria abolido em 1894. Para John Schulz (2013), apesar de que tenha sido fortemente atacado pela imprensa brasileira no seu primeiro ano, esse acordo foi bastante vantajoso aos interesses açucareiros brasileiros, que puderam contar nestes quatro anos com um expressivo crescimento das suas vendas para o Estados Unidos.

A quebra deste tratado fundamentando os receios de perda do mercado estadunidense seria acompanhada de uma queda dos preços nos mercados europeus entre 1890 até 1894. Esse quadro de forte queda nos 
preços se repetiria em 1901 tanto na Europa como no Estados Unidos, afetando ainda mais negativamente a exportação do açúcar brasileiro. A diferença neste momento seria que no Brasil, segundo Dé Carlí (1937), a crise de 1901 atingiu mais intensamente aquela indústria semi-organizada, mais moderna, devido à necessidade de crédito avultado e a inversão de um grande capital. Nesse sentido, considera-se possível assim uma estreita relação entre a tentativa de formação de convênios nos anos de crise do açúcar no mercado mundial. Teria sido possível, também, perceber a influência no abandono desses planos de valorização devido a própria recuperação do mercado, como se daria em 1895 e 1901.

Ora, mas é de contatar por outro lado, que a terceira tentativa dos pernambucanos seria vitoriosa durante alguns anos. Resta examinar aquele convênio que melhor auferiu resultados. Em 1905, foi organizada a Coligação Açucareira de Pernambuco. Eisenberg (1977) oferece uma visão geral da Coligação quando relata que estimulados pelos agentes comerciais Mendes Lima \& Cia (responsáveis pelo financiamento de uma parte da produção do estado), os usineiros aquiesceram em produzir uma porcentagem de açúcar demerara para a exportação, sendo que os armazenadores e agentes comerciais comprometeram-se a não comercializarem os seus estoques no mercado nacional antes de novembro. ${ }^{9}$ Sem dúvida alguma o sucesso levaria a expansão da Coligação, que em 1906, passaria a contar com a adesão dos estados da Bahia, Alagoas e Campos. O projeto não foi de pouco monta. Os dirigentes da Coligação -armazenários e usineiros de Pernambuco- conseguiram controlar as vendas, estabelecer cotas de comercialização, financiar a estocagem e conceder subsídios para os produtores que exportassem o açúcar. Durante dois anos, os preços foram mantidos altos pelo controle dos estoques. Ora, basta dizer que o acordo duraria até 1907 e durante estes dois anos, os preços se mantiveram altos no mercado interno.

Mas, afinal, a cooptação de outros estados, vista como o grande trunfo da luta contra a baixa dos preços, acabou por demonstrar que concretamente o que existia era uma aliança muito precária, facilmente dissolúvel. Deve-se considerar que a postura adotada por Pernambuco de exportar parte da sua safra ou não, como o maior estado produtor do país, influía diretamente no mercado interno, determinando se haveria superabundância do produto no país, e consequentemente, o aviltamento ou não dos preços no mercado interno. Em algum momento, o bom funcionamento das coligações acabava esbarrando no grande número de produtores. Como chamava a atenção o diretor da Sociedade Nacional da Agricultura, era

\footnotetext{
${ }^{9}$ Este convênio contou com o apoio da Sociedade Auxiliadora da Agricultura de Pernambuco, da União dos Sindicatos Agrícolas de Pernambuco e da Sociedade Nacional da Agricultura.
} 
"materialmente impossível realizar um acordo entre mais de quatro mil fabricantes de açúcar disseminados em oito estados para a exportação para o estrangeiro, em proporções rigorosamente exata com a safra de cada um" (A Lavoura, 1911, p. 250). Acrescenta-se a isto, o fato dos estados do Sudeste serem os maiores consumidores, o que tornava ainda mais difícil alcançar o consenso necessário para que o convênio tivesse sucesso.

Um importante crítico das políticas de valorização do açúcar neste período, Júlio Brandão Sobrinho ${ }^{10}$ (1912b), reconhecia que a Coligação Açucareira de Pernambuco dera bons resultados com o estabelecimento de preços mínimos que conseguiram arrefecer a especulação. Para ele, era visível que a fricção do convênio se dera no exato momento de inclusão de outros estados. O papel de elo fraco da corrente recaiu sobre o estado do Rio de Janeiro, mas suscetível à pressão dos comerciantes do Sudeste. Neste caso, é de destacar que estas coligações tiveram como o seu suporte principal firmas de agentes comerciais do Nordeste, como a Mendes, Lima \& Cia., sendo que os planos de valorização não só deixavam de fora os comerciantes e refinadores do Sudeste, mas também contrariavam os seus interesses, já que o ponto alto dos seus negócios era alcançado através da especulação com a oscilação do preço deste produto.

$\mathrm{O}$ contra-ataque organizado pelos comerciantes e refinadores do $\mathrm{Su}-$ deste daria resultados rapidamente, já se podendo prever com facilidade o fim do Convênio Açucareiro do Brasil na safra de 1908-1909. A pressão exercida por estes comerciantes faria com que algumas usinas de Campos concordassem em vender o seu açúcar a preços menores do que os determinados pela coligação. $\mathrm{O}$ coup de grâce seria dado quando os armazenadores do Recife também aquiesceram em vender o seu açúcar a preços abaixo do esperado. Eisenberg (1977), ao escrever sobre a Coligação, aclara que ao depender da cooperação voluntária dos produtores, dos agentes comerciais e dos armazenadores de diferentes estados, atores com interesses muito diversos, esses cartéis estavam sob uma contínua ameaça de desintegração (pp. 52-53). É justamente nesses momentos em que se pode perceber não só o poder que detinham os homens responsáveis pela comercialização do açúcar, mas a disputa entre os seus representantes no Nordeste e no Sudeste, ou seja, os interessados em auferir maiores lucros com a formação de cartéis que garantissem o aumento do preço no mercado interno ou aqueles que estavam mais interessados em especular com o preço do açúcar, posto que os seus estados eram os maiores consumidores.

Em 1909, Pernambuco tentaria organizar uma nova coligação local. A denominada Coligação para a Valorização do Açúcar Ficaria ao car-

\footnotetext{
${ }^{10}$ Júlio Brandão Sobrinho teria vários cargos na Secretária da Agricultura, Comércio e Obras Públicas de São Paulo e foi o representante do estado na Conferência Açucareira de Campos.
} 
go da Sociedade Auxiliadora de Pernambuco e da União dos Sindicatos Agrícolas. A coligação deixaria de ter um caráter consultivo sobre o preço do açúcar, para agir diretamente na sua comercialização através da compra de uma parte da safra pernambucana para manter os preços internos acima de um nível. Desta feita, o plano não sairia do papel, esbarrando na tão malfada dificuldade de conseguir crédito agrícola.

Aliás, essa dificuldade em obter capitais levaria novamente à baila a questão dos prêmios. Este ano seria marcado pela Conferência Açucareira de Campos e por uma alarmante estimativa de uma safra de 4500000 sacos. Sendo que o consumo interno era calculado na faixa dos 3000000 , o que significava exportar 1500000 sacos a qualquer preço ou arcar com as consequências de um excedente muito grande no mercado interno. $\mathrm{O}$ plano seria traçado pelo usineiro e futuro ministro da Agricultura, José Rufino Bezerra Cavalcanti, sendo retomado na conferência por Augusto Ferreira Ramos (Campos, 2001). Neste particular, a diferença estava na forma de garantir o capital necessário. Se, no plano original pensava-se em conseguir este capital através de um imposto de exportação, na versão de Augusto Ferreira Ramos, este capital deveria ser proveniente de um imposto sobre o consumo interno, ou seja, o sistema de prêmios europeus. Embora ambos os planos tenham sido alvo de uma forte oposição mesmo por parte de alguns usineiros e comerciantes, houve uma melhora na cotação do açúcar no mercado externo devido à seca que devastou os campos de beterraba europeus neste ano, o que diminuiu a força dos seus defensores (Brandão, 1912a).

Soma-se a esse quadro inesperado, o descontentamento da população em ver o seu custo de vida sofrer mais um acréscimo em favor de um imposto que só atenderia os interesses dos produtores de açúcar. É quando se observam as páginas de notícia da imprensa é que se percebe a repercussão que teria tal questão. Como era de se esperar, Augusto Ferreira Ramos sofreu duras críticas por não pensar na situação dos consumidores. Defendia-se que os produtores deveriam ter investido mais nas suas usinas e assim baratear o custo da produção, como se fazia em outros países. Os defensores dos prêmios alegavam que os principais responsáveis pela alta dos preços eram os especuladores e que o "justo preço" resguardaria o consumidor das altas inexplicáveis. Para eles, era indiscutível que os únicos que saiam ganhado eram os comerciantes de açúcar, que lucravam imensamente com os "habituais desvios escandalosos e condenáveis [...]. São esses desvios que aos intermediários asseguram oportunidade para as monstruosas extorsões contra os que trabalham" (Brandão, 1912b, p. 37).

Embora, os defensores do "justo preço" se esforçassem para persuadir a população, o resultado seria nulo. Na tentativa de convencer a opinião 
pública, Pereira Lima, ${ }^{11}$ usineiro, que dentro de alguns anos seria ministro da Agricultura, e era neste momento um dos principais articuladores da tentativa de montar o convênio, defendia que não se tratava dos tão malfadados trustes, mas sim de cooperativas de vendas. Embora fosse descrito por Lima Barreto mais tarde em uma das suas crônicas publicadas no Jornal Brás Cubas em julho de 1918, como agente por demais sabido de vários trustes açucareiros, um "judeu do açúcar". Sendo que a população sofria ainda mais com essas negociatas, uma vez que os salários não aumentavam, "enquanto todas as utilidades da vida sobem sempre de preço" (Lima Barreto, 2004, p. 360).

Como quer que seja, o recuo de 1911 não inviabilizou uma nova tentativa em 1913. Como seria de se esperar, desta vez, não se tocaria na questão dos impostos. Retornava-se a velha fórmula pernambucana de exportar uma parte da safra para aumentar o preço no mercado interno. Assim, Pernambuco se comprometia a enviar para o exterior a primeira parte da sua safra, possibilitando um equilíbrio entre a oferta e o consumo nas praças comerciais do Sudeste, o que beneficiaria principalmente os produtores campistas. No mais, 23 usinas campistas que assinaram o acordo se comprometeram a enviar para o estrangeiro metade da porcentagem que Pernambuco exportou do açúcar tipo demerara, "contribuindo assim para a solidariedade com os seus colegas de Pernambuco e em benefício do mercado de açúcar em geral" (Ministério da Agricultura, Indústria e Comércio, 1913). Certo é que a solidariedade dos campistas não chegaria longe e vários signatários burlaram o acordo. Os produtores do Sudeste escorados em seus próprios mercados sabiam que era inviável para Pernambuco não escoar parte da sua safra, arcando com preços baixos tanto no mercado externo quanto no interno. Não é de se admirar, assim, que tantas foram as tentativas e nenhuma tenha ido adiante.

Pode-se facilmente perceber que diferentemente das políticas de valorização do açúcar adotados principalmente na Europa, no Brasil não houve uma atuação direta do Estado. Mesmo quando dois importantes defensores desta estratégia subiram ao poder, José Rufino Bezerra Cavalcanti e José Gonçalves Pereira Lima, o açúcar brasileiro estava em alta devido a primeira guerra mundial. Como se viu, mesmo que o Ministério da Agricultura fosse comandado por homens ligados diretamente ao açúcar, os convênios e acordos seriam relegados ao esquecimento por alguns anos e só voltaram a ser novamente discutidos com a recuperação da indústria açucareira de beterraba na Europa e a passagem da euforia criada pelos altos preços que atingiria quase por igual todos os produtores de açúcar de cana.

${ }^{11}$ Ministro da Agricultura de 26 de novembro de 1917 até 15 de novembro de 1918. 
Embora o Brasil não fosse um dos principais exportadores de açúcar isso não quer dizer que a primeira guerra mundial não tenha influído de forma marcante e beneficamente sobre a sua produção açucareira. $\mathrm{O}$ fato é que a produção de açúcar de beterraba diminuiu extraordinariamente nestes anos. Como não poderia deixar de ser, a posição dos produtores de açúcar brasileiros ficaria mais desafogada pelo aumento significativo das exportações. Na França contribuiria para tal situação dois fatores: a escassez de braços e a invasão de departamentos especializados no cultivo e aproveitamento da beterraba, os quais tiveram suas plantações arrasadas e suas usinas destruídas (A Lavoura, 1924). Naturalmente, o Norte continuaria a ser o principal responsável pela exportação, principalmente quando se olha as estatísticas dos estados de Pernambuco, Alagoas e Sergipe. Nesse momento, os principais compradores do açúcar brasileiro seriam os mesmos: Inglaterra, Uruguai, Argentina e o Estados Unidos. Só que neste caso a demanda seria maior (MAIC, 1918).

Não é raro ler que era necessário que os produtores de açúcar brasileiro aproveitassem a situação criada pela guerra. Não havia como ignorar o crescimento que a guerra ocasionou, seja na expansão da capacidade das fábricas instaladas ou mesmo na multiplicação das usinas. Antônio Carlos Pestana (1922), diretor da Estação Geral Experimental de Campos, revelava que a indústria açucareira campista que estava estagnada até 1914 teve com o início da guerra "um desenvolvimento inédito na história econômica nacional” (p. 13). O Boletim do Ministério da Agricultura, Indústria e Comércio apontava que em 1915, o açúcar de beterraba europeu já era substituído pela produção de Java, Cuba, Brasil e Argentina (Julho-dezembro de 1915 , p. 125).

Mas a realidade após a primeira guerra seria outra e muito diferente para os produtores de açúcar de cana. A recuperação dos campos de beterraba na Europa reacenderia a luta entre os dois tipos de açúcar. O problema da superprodução voltaria novamente a ser um agravante para os produtores de açúcar do Brasil. Após a recuperação da indústria açucareira europeia, a euforia daria lugar aos velhos temores de oscilação dos preços. Em 1926, Pernambuco chegaria a propor a criação do chamado Instituto de Defesa do Açúcar, que teria como objetivo intervir no mercado, para evitar a depressão dos preços, concentrando o recebimento do açúcar, retirado por warrantagem o volume deste produto necessário à manutenção do justo preço, regulando à época das vendas (Azevedo, 1948). Em 1928, os produtores campistas, seguidos por outros estados, organizaram comissão de vendas. Também seria proposto na Reunião Açucareira de 1928, o Plano Geral de Defesa do Açúcar, Aguardente e Álcool, com o mesmo intuito de valorização artificial destes produtos. A crise de 1929 acabaria impedindo que ele fosse colocado em prática. 
Nos anos que saíram deste contexto da guerra ou de secas, se esbarrava na difícil tarefa de reunir os produtores de açúcar. Comentando este período, o futuro presidente do IAA, Barbosa Lima Sobrinho, endossava o fato de este ser um dos principais problemas destes planos: "havia sempre os outsiders, pessoas que ficavam do lado de fora e que se regulavam pelos seus próprios interesses" (Lima Sobrinho, 2002, p. 17). Não é preciso lembrar aqui que no pós-1930, através do IAA, o poder público se fez sentir com a adoção destas mesmas medidas preconizadas anteriormente de modo a suprimir o jogo da lei da oferta e da procura, garantindo a remuneração dos usineiros sob a alegação de que a instabilidade dos preços era prejudicial à agricultura.

\section{COMENTÁRIO FINAL}

Não é difícil perceber que estes planos estavam imbuídos do mesmo espírito, ou seja, controlar a oferta e os preços do açúcar nas praças comerciais do Sudeste. Há nitidamente por parte destes homens a percepção da importância essencial deste mercado na manutenção da indústria açucareira brasileira. A verdade é que o seu peso já era maior que o do mercado externo. Mas como se pode captar não havia como adaptar tais práticas europeias de valorização artificial do açúcar nem colocar em prática o "justo preço" sem o concurso de um dos seus principais atores: o Estado. Não que este não tivesse um papel fundamental neste período na proteção da produção açucareira brasileira, como demonstra Heitor P. de Moura Filho, através dos altos impostos de importação (2012-2013, pp. 221-246). Mas não ao ponto de aplacar as demandas dos homens ligados ao açúcar, que não deixaram de pensar em medidas que remediassem a baixa dos preços. Este trabalho pretendeu contribuir, assim, para dar a devida força ao pensamento que circulava no meio açucareiro durante a Primeira República e as suas repercussões.

Em síntese, embora os prêmios não tenham figurado como uma das políticas de valorização do açúcar neste momento e os convênios açucareiros vigoraram por um curto espaço de tempo, eles tiveram uma importância significativa na composição das medidas que foram implantadas com sucesso pelo IAA no pós-1930. O estudo destas discussões mostra também a importância que o mercado interno passava a ter para a indústria açucareira do país. Nos dois casos em estudo, defendidos mais fortemente pelo região Nordeste ou pelo Sudeste, consta que o conjunto de posições e atitudes que caracterizaram os homens ligados ao açúcar via o mercado externo mais como uma forma de escoar os excedentes que não eram absorvidos pelas praças comerciais do país, na esperança da bem-vinda valorização do seu produto no próprio mercado brasileiro. 


\section{LISTA DE REFERENCIAS}

Almeida, P. R. DE (2001). Formação da diplomacia econômica no Brasil: As relações econômicas internacionais no império. São Paulo: Editora Senac.

Azevedo, F. (1948). Canaviais e engenhos na vida política do Brasil: Ensaio sociológico sobre o elemento político na civilização do açúcar. Rio de Janeiro: IAA.

Barros, M. I. (1905). Trabalhos da Conferência Açucareira do Recife. Recife: Tip. do Diário de Pernambuco, 1905 (Biblioteca do Arquivo Nacional).

Barros, M. I. (1907). Anais do Primeiro Congresso Nacional da Agricultura. Rio de Janeiro: Imprensa Nacional, 1907, vols. 1 e 2 (Biblioteca Nacional).

BRANDÃo, J. (1912a). A lavoura da cana e a indústria açucareira dos estados paulista e fluminense: Campos e Macaé em confronto com São Paulo. Relatório apresentado ao Ilustríssimo e Exm. Sr. Dr. Antônio de Pádua Salles DD. Secretário da Agricultura, Comércio e Obras Públicas por Júlio Brandão Sobrinho chefe dos Estudos Econômicos. São Paulo: Tip. Brazil de Rothchild \& Co. (Biblioteca do Ministério da Fazenda).

BRANDÃo, J. (1912b). Memorial sobre a Quarta Conferência Açucareira realizada em Campos apresentada ao Sr. Diretor Geral da Secretária da Agricultura pelo representante do Governo do Estado Júlio Brandão Sobrinho chefe da sessão de estudos econômicos. São Paulo: Tipografia Brazil de Rothchild (Biblioteca do Museu do Ipiranga).

Brasil (1889/1926). Coleção das leis da República do Brasil. Rio de Janeiro: Imprensa Nacional (Biblioteca Nacional).

Campos, Z. V. (2001). Doce amargo: produtores de açúcar no processo de mudança - Pernambuco (1874-1941). São Paulo: Annablume.

Coimbra, E. (1907). Anais do Primeiro Congresso Nacional da Agricultura. Rio de Janeiro: Imprensa Nacional, 1907, vols. 1 e 2 (Biblioteca Nacional).

COMISSÃo DE INQUÉRITO SOBRE A INDÚSTRIA DO AÇÚCAR NO BRASIL (1907). Indústria açucareira: produção geral e resumos estatísticos sobre o seu grau de desenvolvimento no fim do século XIX. Rio de Janeiro: Imprensa Nacional (Biblioteca Nacional).

Couret, E. (1905). Trabalhos da Conferência Açucareira do Recife. Recife: Tip. do Diário de Pernambuco, 1905 (Biblioteca do Arquivo Nacional).

Couret, E. (1907). Anais do Primeiro Congresso Nacional da Agricultura (vols. 1-2). Rio de Janeiro: Imprensa Nacional (Biblioteca Nacional).

Dé CARLí, G. (1937). O açúcar na formação econômica do Brasil [separata]. In IAA, Anuário Açucareiro. Rio de Janeiro: IAA.

EISENBERG, P. L. (1977). Modernização sem mudança: a indústria açucareira em Pernambuco: 1840-1910. Rio de Janeiro: Paz e Terra/Universidade Estadual de Campinas.

GNaCCARINi, J. C. A. (1997). A economia do açúcar: processo de trabalho e processo de acumulação. En B. FAUSTO (org.), História geral da civilização brasileira. O Brasil republicano: estrutura de poder e economia (1889-1930) (vol. 8). Rio de Janeiro: Bertrand Brasil.

GuYot, I. (1901). The Sugar Question in 1901. Londres: Hugh Press.

InSTITUTO DO AçÚCAR E DO ÁlCOOL [IAA] (1972). Brasil/Açúcar. Rio de Janeiro: IAA. 
Lima Barreto. Revista Brás Cubas (O Franco, 4 de julho de 1918). In Lima Barreto, Toda crônica. Rio de Janeiro, Agir, 2004, 2 vols.

Lima Sobrinho, B. (2002). Barbosa Lima Sobrinho (depoimento, 1987). Rio de Janeiro: CPDOC/Centro da Memória da Eletricidade no Brasil.

Ministério dA Agricultura, Indústria e Comércio [MAic] (maio-julho, 1913). Boletim do Ministério da Agricultura, Indústria e Comércio. Rio de Janeiro: Tipografia do Serviço de Estatística (Biblioteca Nacional).

MAIC (maio-agosto, 1915). Boletim do Ministério da Agricultura, Indústria e Comércio. Rio de Janeiro: Tipografia do Serviço de Estatística (Biblioteca Nacional).

MAIC (julho-dezembro, 1915). Boletim do Ministério da Agricultura, Indústria e Comércio, publicado pelo Serviço de Informação. Rio de Janeiro: Tipografia da Diretória Geral de Estatística (Biblioteca Nacional).

MAIC (maio-agosto, 1918). Boletim do Ministério da Agricultura, Indústria e Comércio. Rio de Janeiro: Tipografia do Serviço de Estatística (Biblioteca Nacional).

Martineau, G. (1910). Sugar, Cane and Beet. Londres: Sir Isaac Pitman \& Sons.

MendonçA, A. (janeiro, 1903) Anais da Conferência Açucareira da Bahia. A Lavoura. Boletim da Sociedade Nacional da Agricultura. Rio de Janeiro: Imprensa Nacional, p. 103 (Biblioteca Nacional).

MendonçA, S. R. DE (1977). A primeira política de valorização do café e sua vinculação com a economia agrícola do Estado do Rio de Janeiro (Dissertação de mestrado). Universidade Federal Fluminense, Niterói.

MendonçA, S. R. DE (agosto, 2008). O Convênio de Taubaté e a agricultura fluminense. Revista Brasileira de Gestão e Desenvolvimento Regional, 4(3), 88.

MourA, H. P. DE (2007). Os países latino americanos e a convenção açucareira de Bruxelas de 1902. Anais do Primeiro Congreso Latinoamericano de Historia Econômica. Montevideo.

MourA, H. P. DE (2012-2013). Os países latino americanos e a Convenção Açucareira de Bruxelas de 1902. Travesía, 14-15, 221-246.

PestanA, A. C. (1922). A indústria açucareira campista em 1922 e o decreto 4567, de 24 de agosto do mesmo ano. Rio de Janeiro: Papelaria Americana (Biblioteca do Arquivo Nacional).

Poliano, L. M. (1945). A sociedade nacional da agricultura. Rio de Janeiro: IAA.

Ramos, A. F. et al. (1907). Anais do Primeiro Congresso Nacional da Agricultura. Rio de Janeiro: Imprensa Nacional, 1907, vols. 1 e 2 (Biblioteca Nacional).

Ramos, A. F. et al. (agosto-dezembro, 1911). Reunião açucareira. In A Lavoura. Boletim da Sociedade Nacional da Agricultura, 2, 273 (Biblioteca Nacional).

Schulz, J. (2013). As crises financeiras da abolição. São Paulo: Universidade de São Paulo. Sociedade Nacional da Agricultura (SNA) (1905). Trabalhos da Conferência Açucareira do Recife. Recife: Tip. do Diário de Pernambuco, 1905 (Biblioteca do Arquivo Nacional). 
Sociedade Nacional da Agricultura (SNA) (janeiro, 1924). Indústria do açúcar: açúcar de cana e açúcar de beterraba. In A Lavoura. Boletim da Sociedade Nacional da Agricultura, 15, 22 (Biblioteca Nacional).

SzmrecsánYi, T. (1979). O planejamento da Agroindústria canavieira do Brasil (1930-1975). São Paulo: Hucitec/Universidade Estadual de Campinas.

Victorino, M. (1907). Anais do Primeiro Congresso Nacional da Agricultura. Rio de Janeiro: Imprensa Nacional, 1907, vols. 1 e 2 (Biblioteca Nacional). 